\title{
Improved cardiac protection with Sabax cardioplegia in Langendorff isolated rat hearts
}

\author{
Perian $\mathrm{M}^{1 *}$, Mărginean $\mathrm{M}^{1}$, Dobreanu $\mathrm{D}^{1,2}$, Scridon Alina ${ }^{1}$ \\ Physiology Department, University of Medicine and Pharmacy of Tîrgu Mureș, Romania \\ 2 Adults Cardiology Department (I), Emergency Institute for Cardiovascular Diseases and Transplantation Tîrgu Mureș, Romania
}

\begin{abstract}
Objective: Cardioplegia is an important step to facilitate cardiac surgery while limiting intraoperative myocardial injury. Although recent advances in cardioplegic arrest methods have significantly contributed to better postoperative outcomes, there is still controversy regarding the optimal composition and temperature of the cardioplegic solution. Accordingly, we aimed to assess whether cold or lukewarm Sabax cardioplegia offer improved myocardial protection compared with the classical Krebs-Henseleit solution. Methods: The hearts of 40 male Wistar rats were isolated and submitted to constant-flow retrograde perfusion using a Langendorff perfusion apparatus. The hearts were randomly assigned to cold Krebs-Henseleit (K-H), cold Sabax, or lukewarm Sabax cardioplegia. The ECG, heart rates, and left ventricular systolic pressures (LVSP) were recorded pre- and post-cardioplegia. The time needed for cardioplegia induction and post-cardioplegia recovery were also noted. Results: Both cold and lukewarm Sabax cardioplegia insured faster induction and faster recovery following isothermic reperfusion compared to the standard $\mathrm{K}-\mathrm{H}$ solution (both $\mathrm{p}<0.01$ ). With $\mathrm{K}-\mathrm{H}$ cardioplegia, the hearts presented a $21.7 \%$ force loss after reperfusion $(\mathrm{p}<$ 0.001), whilst Sabax cardioplegia was associated with a slight increase in ventricular mechanical activity (3\% LVSP increase with lukewarm Sabax cardioplegia, $p<0.001$ and $2 \%$ LVSP increase with cold Sabax cardioplegia, $p=0.02$ ). With Sabax cardioplegia the hearts displayed considerably less major arrhythmic events and presented less significant bradycardia. Conclusions: The present data suggest that Sabax cardioplegia may be superior to the classical cold crystalloid K-H solution in preserving mechanical activity of the heart and may provide superior protection against major arrhythmias.
\end{abstract}

Keywords: experimental model, cardioplegia, Sabax, Langendorff

Received: 19 November 2014 / Accepted: 1 December 2014

\section{Introduction}

Perioperative myocardial damage related to the use of cardiopulmonary bypass, cardioplegic arrest, and subsequent reperfusion of the heart is one of the most significant causes of morbidity and mortality after cardiac surgery [1]. Although recent advances in cardioplegic arrest methods have significantly contributed to better postoperative outcomes, there is still controversy regarding the optimal composition, temperature, and routes of delivery of the cardioplegic solution.

Cold crystalloid and cold blood-based cardioplegia offer the advantage of lowering cardiac oxygen consumption and allowing prolonged myocardial survival during ischemia. Nevertheless, deep myocardial hypothermia decreases the activity of myocardial enzymes, causing delayed myocardial recovery after surgery [2]. Warm blood cardioplegia appears to overcome these drawbacks, providing better myocardial protection and less myocardial injury, although no significant difference was noticed in terms of clinical outcomes [3]. Moreover, the increased risk of hyperkalemia [4], impaired visualization during the construction of coronary anastomoses, and the technical problems encountered particularly in neonatal cardiac surgery [5] limit the utility of this technique. Consequently, there is a wide variation in clinical practice, many centers

* Correspondence to: Marcel Perian

E-mail: marcel_perian@yahoo.com continuing to use crystalloid and/or cold cardioplegia in their routine practice [6, 7].

Recent studies suggest that improved crystalloid cardioplegics may provide superior myocardial protection $[7,8]$. Accordingly, we aimed to assess whether the cold or lukewarm Sabax cardioplegic solution, one of the less known and studied cardioplegics, provides better cardiac protection compared with the standard Krebs-Henseleit solution in Langendorff isolated rat hearts.

\section{Methods}

\section{Animals}

Forty male Wistar rats (body weight, $280 \pm 20 \mathrm{~g}$ ) were acquired from the Experimental Station of the University of Medicine and Pharmacy of Tîrgu Mureș.

All animals were housed in groups of two to three rats per cage in an accredited animal facility, and had free access to standard rat pellets and tap water.

All experiments were performed in compliance with the International Council for Laboratory Animal Science guidelines, Directive 2010/63/EU, and were approved by the local Ethics Committee.

\section{Preparation}

All animals were anesthetized with an intramuscular injection of Ketamine $(75 \mathrm{mg} / \mathrm{Kg})$ and Xylasine $(5 \mathrm{mg} / \mathrm{Kg})$. The abdominal cavity was open and a 3,000 IU dose of heparin 
was injected via the inferior vena cava to prevent coronary thrombosis during heart manipulation [9]. The thorax was open, the hearts were excised and promptly connected to the Langendorff perfusion apparatus (Experimetria Ltd., Budapest, Hungary) via the aorta.

All hearts were allowed 20 min of equilibration under constant-flow retrograde perfusion of oxygenated $(95 \%$ $\mathrm{O} 2+5 \% \mathrm{CO} 2$ ) Krebs-Henseleit solution containing (in mM) $118.0 \mathrm{NaCl}$, 4.7 KCl, 25.0 NaHCO3, 1.2 MgSO4, $1.25 \mathrm{CaCl} 2,1.2 \mathrm{KH} 2 \mathrm{PO} 4$, and 11.0 glucose [10], at $37^{\circ} \mathrm{C}$.

Coronary flow was assessed by collecting the drainage fluid of the coronary perfusate from the right side of the heart via the pulmonary artery. A small catheter was placed in the apex of the left ventricle to prevent the accumulation of any Thebesian flow in the left ventricular cavity.

\section{Cardioplegia protocols}

Following the equilibration period, the hearts were randomly assigned to one of the three cardioplegia protocols - cold Krebs-Henseleit cardioplegia (Krebs-Henseleit; $\mathrm{n}=13$ ), cold Sabax cardioplegia (cold Sabax; $\mathrm{n}=12$ ), or lukewarm Sabax cardioplegia (lukewarm Sabax; $n=15$ ). The Sabax solution contained (in $\mathrm{mM}$ ): $\mathrm{MgCl} 23.2, \mathrm{KCl}$ 24.1, NaHCO3 38.3, $\mathrm{NaCl} 102.5$, and mannitol 68.5.

In the Krebs-Henseleit group, the hearts were perfused with cold $\left(5^{\circ} \mathrm{C}\right)$, oxygenated Krebs-Henseleit solution. Five minutes after the cardioplegic arrest, aortic perfusion was stopped and the hearts were kept arrested for 3 hours in $5^{\circ} \mathrm{C}$ non-oxygenated Krebs-Henseleit solution. After 3 hours of cardioplegic arrest, the hearts were reperfused with Krebs-Henseleit solution at $37^{\circ} \mathrm{C}$.

In the cold Sabax group, the hearts were perfused with cold $\left(5^{\circ} \mathrm{C}\right)$, oxygenated Sabax solution. Five minutes after the cardioplegic arrest, aortic perfusion was stopped and the hearts were kept arrested for 3 hours in $5^{\circ} \mathrm{C}$ non-oxygenated Sabax solution. After 3 hours of cardioplegic arrest, the hearts were reperfused with Krebs-Henseleit solution at $37^{\circ} \mathrm{C}$.

In the lukewarm Sabax group, the hearts were perfused continuously with lukewarm $\left(15^{\circ} \mathrm{C}\right)$, oxygenated Sabax solution for 3 hours, followed by reperfusion with KrebsHenseleit solution at $37^{\circ} \mathrm{C}$.

\section{Evaluation of the mechanical and electrical activity of the heart}

The electrical and mechanical activities of the cannulated hearts, as well as the tissue temperature, were recorded for all groups over 20-min intervals before cardioplegic induction, as well as during cardiac reperfusion. The time needed for cardioplegia induction and the local tissue temperature in the moment of cardioplegia induction were noted. The time needed for recovery was also recorded.

Cardioplegia was considered induced when no electrical activity of the perfused hearts could be recorded. Recovery was defined as the spontaneous reappearance of electrical activity following reperfusion with the Krebs-Henseleit solution at $37^{\circ} \mathrm{C}$.

\section{Temperature monitoring}

Cardiac temperature was monitored using a miniature temperature probe (SEN-06-RTH1; Experimetria Ltd.) placed on the basal epicardial surface of the left ventricle.

\section{Mechanical parameters measurements}

Left ventricular systolic pressure (LVSP) was recorded isovolumetrically using a polyethylene balloon introduced into the left ventricle via the left atrium. The balloon was coupled to a spindle syringe and inflated with $0.4-0.6 \mathrm{~mL}$ of boiled water to obtain a left ventricular end-diastolic pressure $<10 \mathrm{mmHg}$ during equilibration. The pressure waves were recorded with an analog to digital converter (DT-301; Data Translation Inc., Marlboro, MA) using a pressure transducer (SEN-01-BPR1; Experimetria Ltd.). The data was recorded and analyzed using data analysis and display software (DT Measure Foundry; Data Translation Inc.). The values used for between-groups comparisons correspond to the mean values of 10 random LVSP recorded for each heart over 20-min intervals during the equilibration period and the post-cardioplegic recovery period, respectively.

\section{Electrophysiological measurements}

An epicardial monophasic action potential electrode (Hugo Sachs Elektronik-Harvard Apparatus) was placed against the basal region of the left ventricular epicardium. All ECG tracings were visually assessed and all rhythm and conduction disturbances were noted. Ventricular tachycardia (VT) was defined as rapid ventricular rhythm (enlarged and distorted QRS complexes) of at least four beats. Ventricular fibrillation (VF) was defined as a wandering, irregular baseline, with no clearly identifiable QRS complexes or P waves. Atrioventricular block was defined as occasional and/or persistent dissociation of $\mathrm{P}$ waves and QRS complexes. Heart rates were derived from the ECG based on RR intervals duration. The values used for betweengroups comparisons correspond to the mean values of 10 random heart rate values measured for each heart over 20min intervals during the equilibration period and the postcardioplegic recovery period, respectively.

\section{Exclusion criteria}

Any heart with a heart rate lower than $200 \mathrm{bpm}$ and a coronary flow rate higher than $20 \mathrm{~mL} / \mathrm{min}$ or lower than $8 \mathrm{~mL} / \mathrm{min}$ by the end of the equilibration period was excluded from the study. Hearts were also excluded in the case of impossibility to obtain a stable sinus rhythm within the first 5 min of initial Krebs-Henseleit perfusion, loss of mechanical activity before the administration of cardioplegic perfusion, and in the presence of recurrent major arrhythmic events (VT or VF) before cardioplegic induction. Based on these exclusion criteria, 3 hearts were excluded 
from the Krebs-Henseleit group, 2 hearts were excluded from the cold Sabax group, and no heart was excluded from the lukewarm Sabax group.

\section{Statistics}

Data are expressed as means \pm SD. Nonparametric ANOVA (Kruskal-Wallis test) was used for multiple comparisons. Between-group comparisons were performed using the Mann-Whitney $U$ test. Differences within the same group were tested for significance with the paired t-test. A $p$ value of less than 0.05 was considered statistically significant. Statistical analyses were undertaken using GraphPad Prism software (GraphPad Software; San Diego, CA).

\section{Results}

\section{Cardioplegia induction}

With Krebs-Henseleit cardioplegia, cardioplegic arrest occurred $82.1 \pm 6.7 \mathrm{sec}$ after the initiation of the KrebsHenseleit perfusion, whilst in the hearts subjected to both cold and lukewarm Sabax cardioplegia, the time needed for induction was significantly shorter $(58.5 \pm 4.0 \mathrm{sec}$ and 64.2 $\pm 4.5 \mathrm{sec}$, respectively; both $\mathrm{p}<0.01$ ). The time needed for cardioplegia induction was also shorter in the cold Sabax group as compared with that recorded in the lukewarm cardioplegia group $(\mathrm{p}<0.01)$.

Epicardial temperature at the moment of cardioplegia induction was significantly higher in both cold and lukewarm Sabax groups $\left(27.7 \pm 0.4^{\circ} \mathrm{C}\right.$ and $27.9 \pm 0.4^{\circ} \mathrm{C}$, respectively), compared with the Krebs-Henseleit group (8.3 $\pm 0.6^{\circ} \mathrm{C}$; both $\left.\mathrm{p}<0.05\right)$. There was no significant difference in cardiac temperature at the time of cardioplegia induction between the two groups subjected to Sabax cardioplegia $(\mathrm{p}=0.28)$.

\section{Improved cardiac mechanical activity profile with Sa- bax cardioplegia}

During the equilibration interval, the assessment of the mechanical activity of the heart revealed similar LVSP in all three groups $(115 \pm 3 \mathrm{mmHg}$ in the Krebs-Henseleit group versus $113 \pm 4 \mathrm{mmHg}$ in the cold Sabax group versus $115 \pm 5 \mathrm{mmHg}$ in the lukewarm Sabax group, $\mathrm{p}>0.05$ ).

The mean LVSP recorded during post-cardioplegic recovery (Figure 1) in the Krebs-Henseleit group (90 \pm 3 $\mathrm{mmHg}$ ) was significantly lower compared to both cold and lukewarm Sabax groups $(116 \pm 5 \mathrm{mmHg}$ and $119 \pm$ $5 \mathrm{mmHg}$, respectively; $\mathrm{p}<0.01$ ), while no significant difference was noticed between these two latter groups $(\mathrm{p}=$ $0.21)$.

In the Krebs-Henseleit group, cardioplegia was associated with a $25 \mathrm{mmHg}(21.7 \%)$ LVSP loss $(\mathrm{p}<0.001)$. Contrarily, lukewarm Sabax cardioplegia was associated with a $4 \mathrm{mmHg}(3.0 \%)$ LVSP increase $(\mathrm{p}<0.001)$. In the cold Sabax group, a $2 \mathrm{mmHg}(2.0 \%)$ increase in LVSP was also observed during post-cardioplegia recovery compared with pre-cardioplegia recordings $(\mathrm{p}=0.02)$.

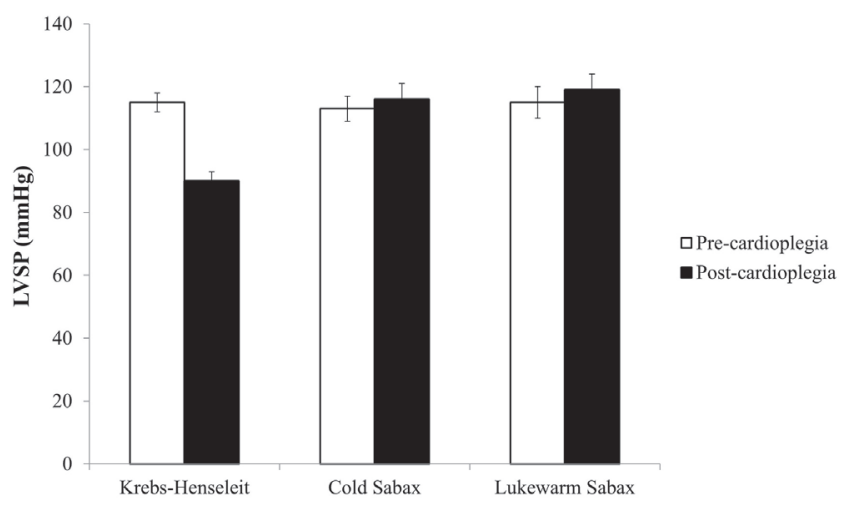

Fig, 1. Left ventricular systolic pressures (LVSP) measured over 20min intervals during the equilibration period (pre-cardioplegia) and post-cardioplegic recovery (post-cardioplegia) in the three study groups. Data are expressed as mean \pm SD. $p \leq 0.02$ between preand post-cardioplegia LVSP for all studied groups.

\section{Spontaneous cardiac arrhythmic events during post- cardioplegia recovery}

During the equilibration period, ECG monitoring showed no arrhythmias or conduction disturbances in neither of the three study groups.

Five episodes of spontaneous VF (Figure 2, A and B), 4 episodes of sustained VT (Figure 2, C), and 3 episodes of high-degree atrioventricular block were recorded during post-cardioplegia recovery in the Krebs-Henseleit group. In the cold Sabax group, ECG monitoring during post-cardioplegia recovery showed 2 episodes of VF, while only 1 episode of VF was recorded in the lukewarm Sabax group, and no VT episodes were recorded in the two Sabax groups. These latter groups also presented 2 episodes of high-degree atrioventricular block each.

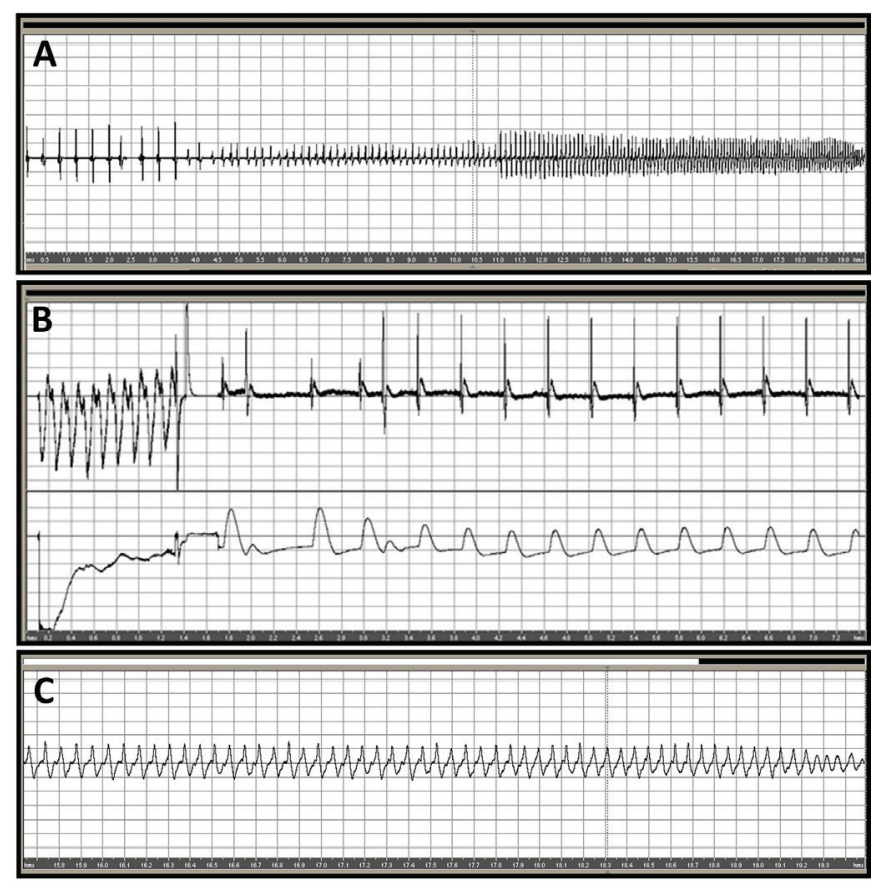

Fig. 2. ECG tracings recorded during post-cardioplegia recovery showing (A) spontaneous ventricular fibrillation; (B) electrical cardioversion of ventricular fibrillation with sinus rhythm restoration; and (C) ventricular tachycardia degenerating into ventricular fibrillation. Panel B depicts simultaneous ECG and LVSP recordings. 
Heart rate changes with different cardioplegia protocols

During the equilibration period, the three study groups presented similar heart rates $(277 \pm 15 \mathrm{bpm}$ in the KrebsHenseleit group versus $273 \pm 6 \mathrm{bpm}$ in the cold Sabax group versus $276 \pm 4 \mathrm{bpm}$ in the lukewarm Sabax group, $\mathrm{p}>0.05$ ).

The mean heart rates recorded during post-cardioplegia recovery (Figure 3) in the Krebs-Henseleit group (204 \pm 4 bpm) were significantly lower compared to both cold and lukewarm Sabax groups $(263 \pm 6 \mathrm{bpm}$ and $268 \pm 5 \mathrm{bpm}$, respectively; $\mathrm{p}<0.01$ ), but no significant difference was noticed between these two latter groups $(\mathrm{p}=0.16)$.

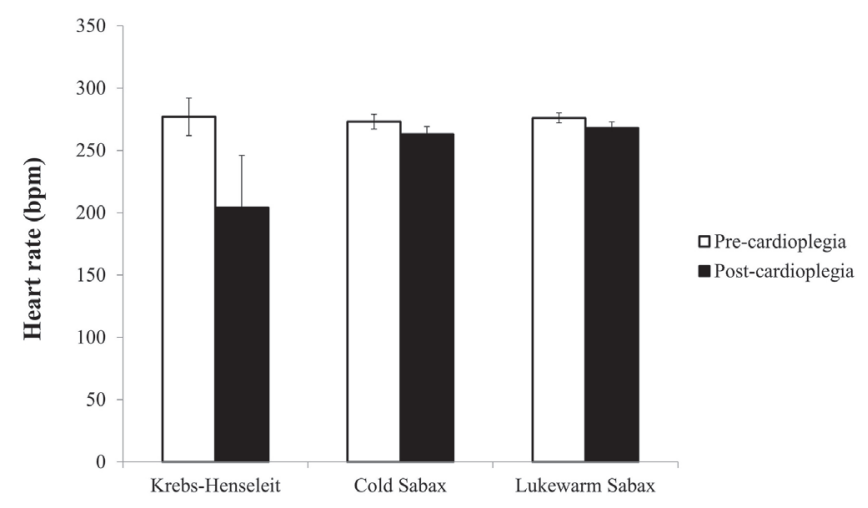

Fig. 3. ECG-derived heart rates measured over 20-min intervals during the equilibration period (pre-cardioplegia) and post-cardioplegic recovery (post-cardioplegia) in the three study groups. Data are expressed as means \pm SD. $p<0.01$ between pre- and postcardioplegia heart rate values for all studied groups.

In the Krebs-Henseleit group, cardioplegia was associated with a $73 \mathrm{bpm}(26.2 \%)$ decrease in heart rate $(\mathrm{p}<$ $0.001)$. Cold Sabax cardioplegia was associated with a 10 bpm $(4.0 \%)$ decrease in heart rate $(\mathrm{p}<0.001)$, whilst in the lukewarm Sabax group, an $8 \mathrm{bpm}(3.0 \%)$ decrease in heart rate was observed during post-cardioplegia recovery compared to pre-cardioplegia recordings $(\mathrm{p}<0.01)$.

\section{Post-cardioplegia recovery}

After reperfusion with isothermic Krebs-Henseleit solution, all hearts recovered their electrical and mechanical activities, regardless of the studied group. The interval needed for recovery was significantly longer in the KrebsHenseleit group compared with both the cold and lukewarm Sabax groups (72.3 sec in the Krebs-Henseleit group versus $54.3 \mathrm{sec}$ in the cold Sabax group versus $40.9 \mathrm{sec}$ in the lukewarm Sabax group, $\mathrm{p}<0.001$ ). The time needed for post-cardioplegic recovery was also shorter in the lukewarm Sabax group as compared with that recorded in the cold Sabax group $(\mathrm{p}<0.001)$.

\section{Discussion}

The main findings of the present study were: 1) Sabax solutions insured faster cardioplegia induction and 2) faster recovery following isothermic reperfusion compared to the standard Krebs-Henseleit solution; 3) the shortest induction and recovery intervals were obtained with lukewarm Sabax cardioplegia; 4) while with Krebs-Henseleit cardioplegia LVSP was significantly reduced after reperfusion, Sabax cardioplegia was associated with significantly improved ventricular mechanical activity; 5) with Sabax cardioplegia, the hearts displayed considerably less major arrhythmic events; and 6) presented less significant bradycardia.

Cardioplegia protocols are mandatory for providing myocardial protection whilst ensuring a motionless operating field during cardiac surgery. While cold crystalloid cardioplegia ensures myocardial protection by decreasing myocardial oxygen requirements [11], warm blood cardioplegia was considered to improve metabolic and functional recovery of the myocardium [3] and has therefore been adopted by many surgical teams. However, studies such as the Emory Trial failed to demonstrate better myocardial protection with warm cardioplegia and reported significantly higher rates of neurological events in this group [12]. Thus, the question if warm cardioplegia is superior to cold crystalloid cardioplegia in minimizing cardiac surgery-related myocardial injury is still pending. Recent data suggest that lukewarm or mild hypothermic cardioplegia might provide an answer [13, 14]. Additionally, modified crystalloid cardioplegics, such as cardioplegics with increased osmolarity or mannitol-based cardioplegics may further contribute to better myocardial protection [15]. Accordingly, we sought to assess the cardioprotective effects of the cold and lukewarm Sabax cardioplegic solution, a less studied mannitol-based cardioplegic with high osmolarity.

\section{Faster cardioplegia induction and faster post-cardio- plegia recovery with the Sabax solution}

In both Sabax groups cardioplegic arrest occurred earlier compared with the classical cold Krebs-Henseleit group. The low potassium content of the Krebs-Henseleit solution compared with the Sabax solution may explain this finding. As expected, decreased temperature of the cold Sabax solution further decreased the time needed for cardioplegia induction.

More importantly, Sabax cardioplegia also ensured faster post-cardioplegia recovery, the shortest recovery time being observed with lukewarm Sabax cardioplegia. As a surrogate marker for metabolic and functional myocardial recovery, the shorter interval of time needed for postcardioplegia recovery with Sabax suggests that the Sabax cardioplegic solution may provide superior myocardial protection compared with the standard Krebs-Henseleit solution. Indeed, although standard cold crystalloid cardioplegics ensure good clinical outcomes, one of their main drawbacks remains the delayed postoperative myocardial recovery [2]. Additionally, the proper oxygenation of the lukewarm Sabax cardioplegic solution throughout the pro- 
tocol may have also contributed to this finding, ensuring improved myocardial protection. However, this protection only appears to occur when oxygenation is performed using carbogen mixture $(95 \% \mathrm{O} 2$ and 5\% CO2), while pure oxygen seems to have deleterious effects on myocardial preservation [16].

\section{Improved cardiac mechanical activity and decreased cardiac arrhythmogenicity with Sabax cardioplegia}

The dynamics of LVSP following cardioplegia is commonly used as a sensitive marker of myocardial injury. Decreased LVSP post-cardioplegia is considered to be a direct consequence of inadequate myocardial protection and was found to be a strong predictor of both early and late postoperative death, prolonged hospital stay and cost [17].

In the present study, the Krebs-Henseleit group showed a $21.7 \%$ decrease in LVSP, while no contractile force loss was observed in neither of the Sabax groups. On the contrary, these later groups demonstrated slight, but statistically significant, increases in LVSP. Myocardial edema associated with standard cardioplegia seems to play a pivotal role in the mechanism of cardioplegia-related myocardial force loss [15]. Incomplete cardioplegic protection with these solutions appears to impair the ability of the myocardium to maintain interstitial and intracellular fluid homeostasis, causing myocyte and interstitial edema, which further contribute to myocardial force loss [18]. The presence of mannitol in the Sabax solution may therefore provide additional myocardial protection, significantly decreasing myocardial water content. Similar results were reported with a histidine-buffered tryptophan ketoglutarate cardioplegic solution containing mannitol [15].

Additionally, the high osmolarity of the Sabax solution may have also contributed to the positive inotropic effect observed with Sabax cardioplegia compared with the Krebs-Henseleit cardioplegia. The underlying mechanism seems to be also related to water imbalance, osmotic stress being known to reduce $\mathrm{Ca} 2+$ sensitivity in rat myocardium [19].

On the other hand, there was no significant difference in LVSP between the two Sabax cardioplegia protocols, suggesting that the composition of the cardioplegic solution may actually be more important than its temperature. Indeed, Buckberg et al. demonstrated that electromechanical arrest alone decreases myocardial oxygen requirements by nearly $90 \%$, with only a slight further decrease when lowering myocardial temperature [20]. A recent meta-analysis also demonstrated similar low output syndrome incidence and intra-aortic balloon pump usage with cold and warm cardioplegia [3].

The $26.2 \%$ decrease in heart rate with Krebs-Henseleit cardioplegia while only slight bradycardia was noted in both Sabax groups further supports the hypothesis that Sabax solution ensures better myocardial protection. Additionally, the rate of major ventricular arrhythmias and atrioventricular conduction disturbances was also consid- erably lower in Sabax groups compared with the KrebsHenseleit group. Similar antiarrhythmic effects were reported with Custodiol cardioplegia, another mannitol-rich cardioplegic solution [21]. Besides providing an osmotic effect, mannitol may also improve myocardial protection due to its free-radical scavenging effect [22], limiting postischemic free radicals injuries.

\section{Limitations}

Although the present study strongly suggests improved myocardial protection with the mannitol-based high osmolarity Sabax cardioplegic solution, given that the isolated rat heart model is far from the clinical situation, these results might not be entirely extrapolated to human cardioplegia. Therefore, the Sabax solution may need to be tested in more relevant models and against the widely used blood cardioplegia. Also, isothermic Sabax cardioplegia, which was not tested in the present study, may provide additional myocardial protection.

\section{Conclusion}

The present study demonstrated faster induction and, more importantly, faster post-cardioplegia recovery with Sabax cardioplegia compared with the standard KrebsHenseleit cardioplegia. While with Krebs-Henseleit cardioplegia LVSP was significantly reduced after reperfusion, Sabax cardioplegia was associated with significantly improved ventricular mechanical activity. Additionally, with Sabax cardioplegia the hearts displayed considerably less major arrhythmic events and presented less significant bradycardia. Overall, these data suggest that Sabax cardioplegia may be superior to the classical cold crystalloid Krebs-Henseleit solution in preserving mechanical activity of the heart and may provide superior protection against major arrhythmias.

\section{Acknowledgements}

This work was partially supported by the University of Medicine and Pharmacy of Tîrgu Mureș Research Grant number 16/11.12.2013. The authors report no relationships that could be construed as a conflict of interest.

\section{References}

1. Turer AT, Hill JA. Pathogenesis of myocardial ischemia reperfusion injury and rationale for therapy. Am J Cardiol. 2010;106(3):360-368.

2. Fremes SE, Weisel RD, Mickle DA, et al. Myocardial metabolism and ventricular function following cold potassium cardioplegia. J Thorac Cardiovasc Surg. 1985;89:531-546.

3. Fan Y, Zhang AM, Xiao YB, Weng YG, Hetzer R. Warm versus cold cardioplegia for heart surgery: a meta-analysis. Eur J Cardiothorac Surg. 2010;37(4):912-919.

4. Kao YJ, Mian T, Kleinman S, Racz GB. Hyperkalaemia: a complication of warm heart surgery. Can J Anaesth. 1993;40:67-70.

5. Hickey E, Karamlou T, You J, Ungerleider RM. Effects of circuit miniaturization in reducing inflammatory response to infant cardiopulmonary bypass by elimination of allogeneic blood products. Ann Thorac Surg. 2006;81:S2367-S2372.

6. Ovrum E, Tangen G, Tollofsrud S, et al. Cold blood versus cold crystalloid cardioplegia: a prospective randomized study of 345 aortic valve patients. Eur J Cardiothorac Surg. 2010;38:745-749. 
7. Minasian SM, Galagudza MM, Dmitriev YV, Kurapeev DI, Vlasov TD. Myocardial protection against global ischemia with Krebs-Henseleit bufferbased cardioplegic solution. J Cardiothorac Surg. 2013;8:60.

8. Nakamura $\mathrm{Y}$, Taremoto $\mathrm{N}$, Kuroda H, Ongi S. The advantages of normocalcemic continuous warm cardioplegia over low calcemic cardioplegia in myocardial protection. Surg Today. 1999;29:884-889.

9. Tevaearai HT, Eckhart AD, Shotwell KF, Wilson K, Koch WJ. Ventricular dysfunction after cardioplegic arrest is improved after myocardial gene transfer of a beta-adrenergic receptor kinase inhibitor. Circulation. 2001;104(17):2069-2074.

10. Fukuhiro Y, Wowk M, Ou R, Rosenfeldt F, Pepe S.Cardioplegic strategies for calcium control: low $\mathrm{Ca}(2+)$, high $\mathrm{Mg}(2+)$, citrate, or $\mathrm{Na}(+) / \mathrm{H}(+)$ exchange inhibitor HOE-642. Circulation. 2000;102(19):III319-III325.

11. Tang XN, Yenari MA. Hypothermia as a cytoprotective strategy in ischemic tissue injury. Ageing Res Rev. 2010;9:61-68.

12. Craver JM, Bufkin BL, Weintraub WS, Guyton RA. Neurologic events after coronary bypass grafting: further observations with warm cardioplegia. Ann Thorac Surg. 1995;59(6):1429-1433.

13. Tissier R, Chenoune M, Ghaleh B, et al. The small chill: mild hypothermia for cardioprotection? Cardiovasc Res. 2010;88:406-414.

14. Hale SL, Kloner RA. Mild hypothermia as a cardioprotective approach for acute myocardial infarction: laboratory to clinical application. J Cardiovasc Pharmacol Ther. 2011;16:131-139.
15. Sauer H, Allen SJ, Laine GA. Impact of crystalloid HTK and St. Thomas' cardioplegia on myocardial fluid balance and postcardioplegic stunning. Cardiovasc Eng. 2003;8(1):58-65.

16. Lochner A, Lloyd L, Brits W, Coetzee A. Oxygenation of cardioplegic solutions: a note of caution. Ann Thorac Surg. 1991;51(5):777-787.

17. The Warm Heart Investigators. Randomised trial of normothermic versus hypothermic coronary bypass surgery. Lancet. 1994;343(8897):559-563.

18. Shaffer RF, Baumgarten CM, Damiano RJ Jr. Prevention of cellular edema directly caused by hypothermic cardioplegia: studies in isolated human and rabbit atrial myocytes. J Thorac Cardiovasc Surg. 1998;115(5):11891195.

19. Haim SA, Hayam G, Edoute Y, Better OS. Effect of hypertonicity on contractility of isolated working rat left ventricle. Cardiovasc Res. 1992;26(4):379-382.

20. Buckberg GD, Brazier JR, Nelson RL, et al. Studies on the effects of hypothermia on regional myocardial blood flow and metabolism during cardiopulmonary bypass. J Thorac Cardiovasc Surg. 1977;73:87-94.

21. Edelman JJ, Seco M, Dunne B, et al. Custodiol for myocardial protection and preservation: a systematic review. Ann Cardiothorac Surg. 2013;2(6):717-728.

22. Forman MB, Puett DW, Virmani R. Endothelial and myocardial injury during ischemia and reperfusion: pathogenesis and therapeutic implications. J Am Coll Cardiol. 1989;13(2):450-459. 